\title{
Robotic Ureteral Reimplantation
}

\author{
Niccolo Passoni, MD and Craig A. Peters, MD
}

\begin{abstract}
Minimally invasive techniques have gained popularity in pediatric surgery. Among these, is the robotic approach for ureteral reimplantation in children with vesico-ureteral reflux. We describe main indications of this surgery, our surgical technique as well as trouble shooting of anatomical variants and the post-operative management. We also provide a description of other techniques described in the literature and a brief review of outcomes of published series.
\end{abstract}

Keywords: vesicoureteral reflux, robotic surgery, ureteral reimplantation, pediatric

\section{Indications}

W E RECOMMEND OFFERING robot-assisted laparoscopic ureteral reimplant to children with persistent grade IV to $\mathrm{V}$ vesicoureteral reflux, breakthrough infections, progressive renal scarring, and/or parental requests.

The robotic approach is not usually offered to patients who have a ureterocele. However, robotic reimplant associated with ureteral tapering in children with very dilated ureters is feasible, but should be performed by experienced robotic surgeons, despite absence of data comparing outcome with open tapering.

Finally, there is no consensus regarding at which age it is appropriate to offer a robotic approach $v s$ a standard open surgery. The pneumoperitoneum in the pediatric population offers a smaller working space. In adults, an inflated peritoneum allows for 5 to $6 \mathrm{~L}$ of intra-abdominal volume, whereas in a 1-year-old child only $1 \mathrm{~L}$. Furthermore, a smaller abdominal surface in children limits port placement, requiring more careful planning. ${ }^{3}$ Finally, the relative benefits in smaller children may be less than in older children.

\section{Preoperative Preparation}

The day before surgery, the family is instructed to feed a clear liquid diet to the child. We do not routinely administer bowel preparation. Appropriate intravenous antibiotics are administered at the time of induction.

\section{Patient Positioning}

The patient is positioned supine on the operating room table with straight legs. If the child is taller and/or older, the legs can be split with spreader bars to allow for docking between the legs, unless a DaVinci Xi system is used that allows for side docking. The Si system can be used with side docking as well in taller children without compromise to access. The bed is then moved into a 30-degree Trendelenburg position.

\section{Surgical Steps}

A urethral catheter appropriate for the patient's age is placed once the child had been prepared and draped in a sterile manner. Preoperative cystoscopy is performed if there is a suspicion of ectopic ureteral insertion, but otherwise is not necessary. Ureteral catheters are not routinely used.

The surgery is performed using the da Vinci Surgical robot. An 8.5 or $12 \mathrm{~mm}$ camera port is placed at the umbilicus using a box stitch modification of the Hasson technique. ${ }^{4} \mathrm{We}$ routinely use a 30 -degree $30 \mathrm{~mm}$ scope. Two working ports, either 8.5 or $11 \mathrm{~mm}$, are placed under direct vision in the midclavicular lines. In children older than 3 years of age, the working ports are placed below the level of the umbilicus, whereas in younger patients, they are placed on a transverse line crossing the umbilicus.

To minimize scar visibility, we implemented the HIdES (Hidden Incision Endoscopic Surgery) technique for trocar placement, which was first described for robot-assisted pyeloplasty. ${ }^{5}$ Briefly, the HIdES technique involves making the skin incision for the two working trocars at the Pfannenstiel line. As the trocar is inserted, it is angled cranial, allowing for a higher fascial incision (Fig. 1).

To prevent dislodgment of the trocars, attributable to the reduced thickness of the pediatric abdominal wall, they are secured using a fascial fixation suture and Tegaderm.

Pediatric Urology, Children's Health Texas, University of Texas Southwestern Medical Center, Dallas, Texas, USA. 
The robot is then docked at the end of the table (between the patient's legs if the child is older) or at the side of the table. We normally use a Maryland grasper in the left arm, attached to bipolar cautery, and a monopolar hook or scissors in the right arm.

The first step involves incising the reflection of the peritoneum at the bladder. In female patients, the incision is made along the uterovesical reflection, whereas in males, it is distal to the vas deferens on the bladder reflection of the peritoneum. The peritoneum is then dissected caudally off the bladder until the ureter is encountered. To facilitate this exposure, the bladder is emptied completely. Once identified, the ureter is dissected for 4 to $5 \mathrm{~cm}$ proximal to its insertion in the bladder detrusor. Umbilical tape can be used to facilitate atraumatic handling of the ureter, although this is not required. Careful dissection is performed on the ureteral surface and minimizing use of cautery to prevent strictures or urine leaks. Some authors also report that careful ureteral dissection avoids damage to the neurovascular bundle, preventing postoperative retention. 6,7

At this point, a 3-0 polyglactin acid suture on an $\mathrm{SH}$ needle can be used as a hitch stitch to facilitate traction to the opposite side of ureter that is being reimplanted (Fig. 2). This is passed suprapubically into the peritoneal cavity with a partially straightened needle. The bladder is then partially filled, and a detrusorotomy is performed, with care not to incise the mucosa. As the bladder is being filled, the natural course of the ureter is observed, to make the detrusorotomy along the natural course of the ureter. This is to prevent angulations once the ureter is reimplanted.

Incision of the detrusor is performed with a combination of electrocautery and sharp dissection. If the bladder mucosa is accidentally incised, this can be repaired with a 5-0 polyglactin or chromic suture. The detrusor is then dissected laterally from the mucosa, to create muscular flaps that will create the detrusor tunnel (Fig. 3).

Some authors report placing a 5-0 polydioxanone suture (PDS) stitch at the apex of the detrusorotomy through the ureteral adventitia to avoid retraction of the ureter after the procedure. This is not essential with adequate ureteral mobilization and a sufficient tunnel.

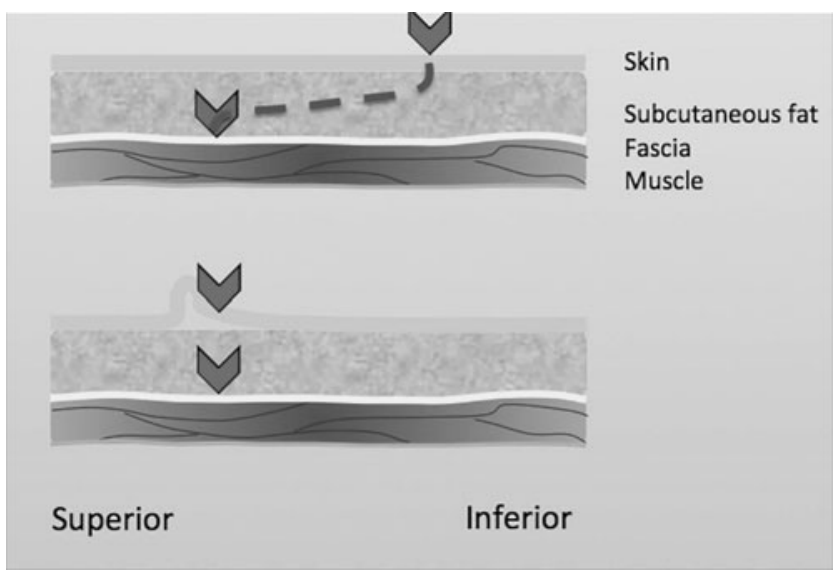

FIG. 1. Diagram illustrating the placement of the trocars in the HIdES method to have the working ports lower on the abdomen. HIdES = hidden incision endoscopic surgery.

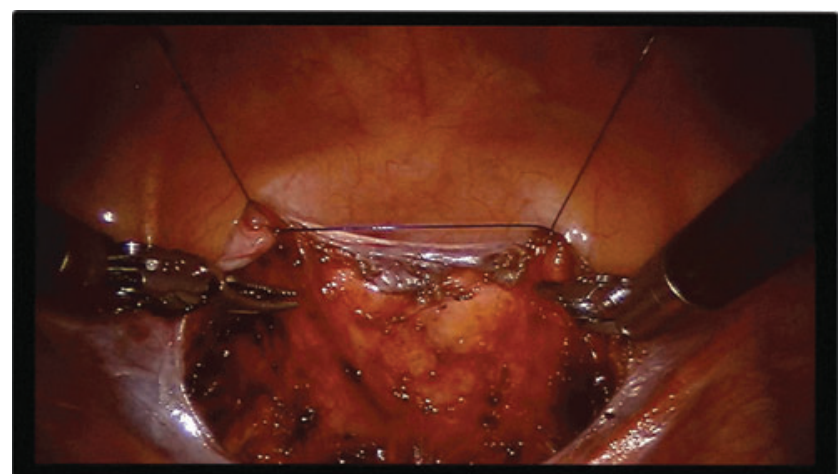

FIG. 2. Illustration of the view provided with the hitch stitch that lifts the entire back wall of the bladder to expose both ureters. It is important to use a braided suture and to loop the hitch stitch around itself to keep providing a spreading effect on the bladder wall.

The ureter is then positioned in the tunnel and the detrusor flaps are closed over it with five to seven interrupted 4-0 polyglactin stitches, for $\sim 2.5$ to $3.5 \mathrm{~cm}$. We do not strictly strive for the 4 to $5: 1$ ratio that is traditionally recommended for open reimplants attributable to the variability in measuring the detrusor tunnel in different degrees of bladder distention (Fig. 4).

We do not incorporate the adventitia into the suturing. Interrupted sutures are preferred over running to prevent failure of the procedure in case the suture loosens from the detrusor tissue.

The closure does not have to be too tight, and it should allow for easy placement of one prong of the needle driver. The peritoneum can be closed with a running 4-0 polyglactin suture, although this is not essential.

At the end of the procedure, we check for hemostasis by reducing the pneumoperitoneum. Ports are removed and the fascia is closed at each site with the preplaced 3-0 polyglactin sutures and skin with a monofilament.

\section{Postoperative Care}

Patients are usually admitted for one night for observation. We usually leave a catheter overnight if a bilateral reimplant is performed, but for unilateral procedures, no

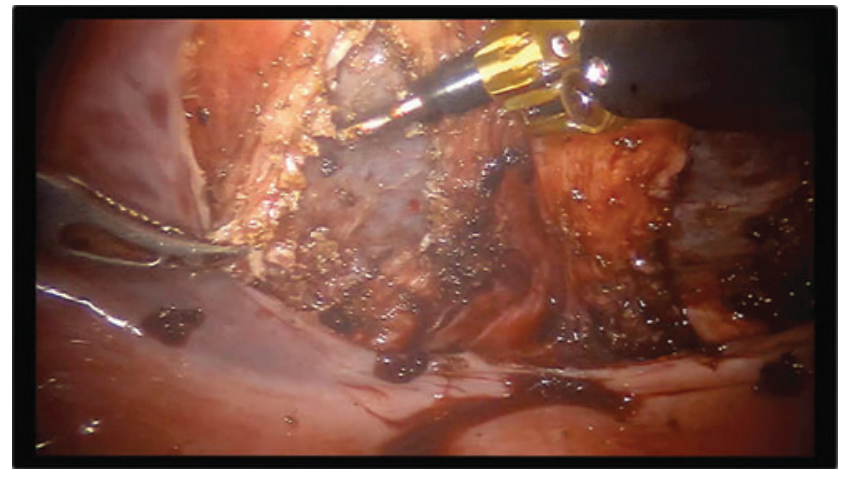

FIG. 3. Creation of the detrusor tunnel with the detrusorotomy. This can be performed with the hook cautery or the hot shears. A small amount of the detrusor is lifted off the mucosa to provide a flap for coverage of the ureter. 


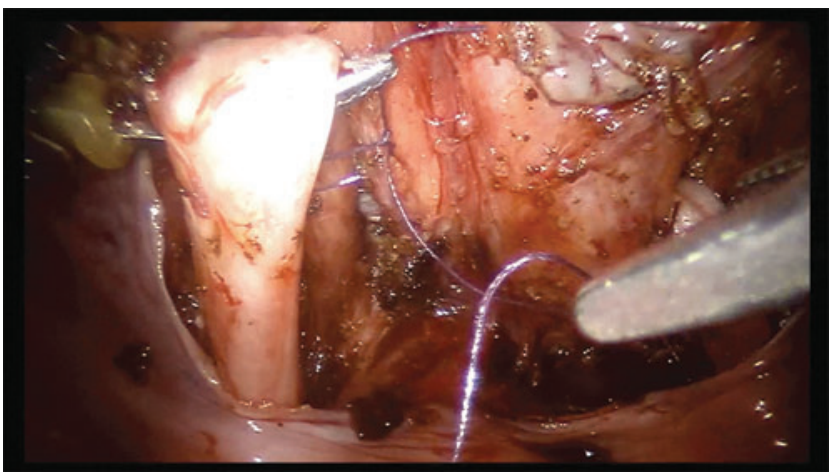

FIG. 4. The ureter is being placed into the detrusor tunnel and the first stitch is being tied. By lifting the ureter and taking tension off the suture, it can be easily tied. Subsequent sutures are interrupted and readily placed with the ureter in situ.

catheter is left in most cases. The morning after, if a catheter has been placed, it is removed if the urine is not too bloody. Then we ensure the child is able to void appropriately at least two times before discharge. Children who failed two voiding trials are discharged home with a Foley catheter in place for 3 to 7 days.

Pain is controlled with IV ketorolac (if the child has no underlying renal dysfunction) the day of surgery and subsequently with oral acetaminophen and ibuprofen. Other discharge criteria include absence of fevers, being able to tolerate a regular diet, adequate pain control with only oral medications, and ambulation.

Patients are discharged on oral antibiotic prophylaxis for 3 months. A renal ultrasound is obtained at 4 weeks postoperatively. At 3 months, we routinely perform a voiding cystourethrogram, unless the family refuses it. At the current state of this technology, we feel it is important to verify resolution of the reflux (Table 1).

\section{Troubleshooting: Anatomical Anomalies, Obesity, Previous Surgeries, and so on}

In case of complete ureteral duplication, a common sheath reimplant can be performed in the same manner.
Caution should be made in creating a wider intradetrusor tunnel to avoid obstruction and provide an adequate antireflux mechanism.

For megaureter cases, we first recommend fully mobilizing the ureter. For tapering the ureter, we recommend mobilizing the ureter up to the iliac vessels. Excessive ureteral tissue is excised by cutting the ureter in a parallel plane on its anterior surface. Before the excision, a hitch stitch is placed, to stabilize the ureter during the entire process. The edges of the ureter are reapproximated using a running 5-0 monocryl suture and then covered with a layer of adventitia. The ureter is then dismembered for obstructive cases and reanastomosed to the mucosa of the bladder before placement in the detrusor tunnel. A stent is left in place for these cases, usually attached to an extraction string brought out the urethra.

\section{Alternate Approaches/Modifications}

The transvesicoscopic approach, originally developed laparoscopically, has also been described robotically. This technique replicates the Cohen procedure commonly performed with an open approach. ${ }^{8-10}$

In this approach, the three trocars are inserted suprapubically into the bladder. The procedure begins with cystoscopy. Instead of water-based solutions, the bladder is insufflated with $\mathrm{CO}_{2}$. To facilitate placement into the bladder and avoid injury to intra-abdominal organs, the bladder is suspended to the abdominal wall. An 18-guage spinal needle is passed into the bladder through the anterior abdominal wall, to allow passage of a suture into the bladder. The spinal needle is then replaced and the tail of the suture is passed through the needle to the outside of the body. Three of these sutures are placed, just proximally to the location of the ports. The ports are places as cranially as possible, to avoid pneumoperitoneum. In such an event, the bladder can be distorted, and a Verres needle can be used to vent the peritoneal cavity. The camera port is placed in the midline, with a 30-degree scope. Two $5 \mathrm{~mm}$ working ports are placed laterally and slightly caudal.

A $3.5 \mathrm{~F}$ feeding tube is placed through the ureteral orifice and it is fixed to it using a 5-0 chromic suture. The hook

TABle 1. Reported Outcomes

\begin{tabular}{|c|c|c|c|c|c|c|}
\hline Series & $\begin{array}{l}\text { Number } \\
\text { of patients }\end{array}$ & $\begin{array}{l}\text { Number of } \\
\text { reimplants }\end{array}$ & $\begin{array}{l}\text { Mean age } \\
\text { of patients }\end{array}$ & $\begin{array}{c}\text { Mean } \\
\text { follow-up } \\
\text { (months) }\end{array}$ & Resolution of reflux & $\begin{array}{l}\text { Method of } \\
\text { success }\end{array}$ \\
\hline Smith et al. ${ }^{4}$ & 25 & 33 & 21 months & 16 & $\begin{array}{l}\text { 100\% unilateral; } \\
88 \% \text { bilateral: }\end{array}$ & Radiographic \\
\hline $\begin{array}{l}\text { Marchini } \\
\quad\left(\text { extra-vesical) et al }{ }^{11}\right.\end{array}$ & 20 & 30 & 8.6 years & 12 & $\begin{array}{l}95 \% \text { clinical; } \\
100 \% \text { radiographic: }\end{array}$ & $\begin{array}{l}\text { Clinical and } \\
\text { radiographic }\end{array}$ \\
\hline $\begin{array}{l}\text { Marchini } \\
\quad \text { (intravesical) et al. }{ }^{11}\end{array}$ & 19 & 36 & 9.9 years & 19.4 & $\begin{array}{l}\text { 100\% clinical; } \\
92.2 \% \text { radiographic }\end{array}$ & $\begin{array}{l}\text { Clinical and } \\
\text { radiographic }\end{array}$ \\
\hline Akhavan et al. & 50 & 78 & 7.2 years & 14 & $\begin{array}{l}90 \% \text { clinical; } \\
92.3 \% \text { radiographic; }\end{array}$ & $\begin{array}{l}\text { Clinical and } \\
\text { radiographic }\end{array}$ \\
\hline Schomburg et al. ${ }^{13}$ & 20 & 25 & 74 months & 13 & $\begin{array}{l}\text { 95\% clinical; } \\
100 \% \text { radiographic; }\end{array}$ & $\begin{array}{l}\text { Clinical and } \\
\text { radiographic }\end{array}$ \\
\hline Arlen et al. ${ }^{14}$ & 17 & 17 & 9.3 years & 16.6 & $\begin{array}{l}94.1 \% \text { clinical; } \\
100 \% \text { radiographic }\end{array}$ & $\begin{array}{l}\text { Clinical and } \\
\text { radiographic }\end{array}$ \\
\hline Herz et al. ${ }^{15}$ & 54 & 72 & 4.9 years & - & $\begin{array}{l}91.7 \% \text { unilateral; } \\
77.8 \% \text { bilateral; }\end{array}$ & Radiographic \\
\hline Boysen et al. ${ }^{16}$ & 260 & 363 & 6.4 years & - & $87.9 \%$ & Radiographic \\
\hline
\end{tabular}


cautery is then used to incise the mucosa around the ureteral orifice and the ureter is mobilized into the bladder with a combination of sharp and electrocautery dissection, as it is usually done in the open setting.

Once the ureter reaches the opposite site of the bladder, the posterior detrusorotomy is reduced with a 4-0 polyglactin suture. Then, the mucosal tunnel is created by gently lifting the mucosa with a Maryland grasper and dissecting it off the detrusor with scissors in a sharp manner. The ureter is then secured into its new location with interrupted 5-0 monocryl stitches.

The ports are then removed and the bladder mucosa is closed with a 3-0 polyglactin suture in a similar manner as it was fixed at the beginning of the case. This is performed carefully to avoid incorporation of the fascia in the bladder closure. Fascia and skin are then closed in the usual manner.

\section{Recommended Videos from Videourology}

1. Videourology 2013, Vol. 27, No. 4

Salvage Endoscopic Correction of High-Grade Vesicoureteral Reflux After Unsuccessful Cross-Trigonal Ureteral Reimplantation

Guy Hidas, Arman Walia, and Antoine Khoury

https://www.liebertpub.com/doi/10.1089/vid.2012.0059

2. Videourology 2018, Vol. 32, No. 5

Robot-Assisted Laparoscopic Dismembered Ureteral Reimplantation with Extracorporeal Tapering for Megaureter

Laura B. Cornwell, Jared Manwaring, and Jonathan V. Riddell

https:/www.liebertpub.com/doi/full/10.1089/vid.2018.0008

\section{Author Disclosure Statement}

No competing financial interests exist.

\section{Funding Information}

No funding was received for this article.

\section{Supplementary Data}

Supplementary Video S1

\section{References}

1. Bowen DK, Faasse MA, Liu DB, Gong EM, Lindgren BW, Johnson EK. Use of pediatric open, laparoscopic and robot-assisted laparoscopic ureteral reimplantation in the United States: 2000 to 2012. J Urol 2016;196:207-212.

2. Ehrlich RM, Gershman A, Fuchs G. Laparoscopic vesicoureteroplasty in children: Initial case reports. Urology 1994;43:255-261.

3. Van Batavia JP, Casale P. Robotic surgery of the kidney and ureter in pediatric patients. Curr Urol Rep 2013;14: 373-378.

4. Smith RP, Oliver JL, Peters CA. Pediatric robotic extravesical ureteral reimplantation: Comparison with open surgery. J Urol 2011;185:1876-1881.
5. Gargollo PC. Hidden incision endoscopic surgery: Description of technique, parental satisfaction and applications. J Urol 2011;185:1425-1431.

6. Casale P, Patel RP, Kolon TF. Nerve sparing robotic extravesical ureteral reimplantation. J Urol 2008;179:19871989; discussion 90.

7. David S, Kelly C, Poppas DP. Nerve sparing extravesical repair of bilateral vesicoureteral reflux: Description of technique and evaluation of urinary retention. J Urol 2004; 172(4 Pt 2):1617-1620; discussion 20.

8. Peters CA, Woo R. Intravesical robotically assisted bilateral ureteral reimplantation. J Endourol 2005;19:618-621; discussion 21-22.

9. Schober MS, Jayanthi VR. Vesicoscopic ureteral reimplant: Is there a role in the age of robotics? Urol Clin North Am 2015;42:53-59.

10. Valla JS, Steyaert H, Griffin SJ, Lauron J, Fragoso AC, Arnaud P, Léculée R. Transvesicoscopic Cohen ureteric reimplantation for vesicoureteral reflux in children: A singlecentre 5-year experience. J Pediatr Urol 2009;5:466-471.

11. Marchini GS, Hong YK, Minnillo BJ, et al. Robotic assisted laparoscopic ureteral reimplantation in children: Case matched comparative study with open surgical approach. J Urol 2011;185:1870-1875.

12. Akhavan A, Avery D, Lendvay TS. Robot-assisted extravesical ureteral reimplantation: Outcomes and conclusions from 78 ureters. J Pediatr Urol 2014;10:864-868.

13. Schomburg JL, Haberman K, Willihnganz-Lawson KH, Shukla AR. Robot-assisted laparoscopic ureteral reimplantation: A single surgeon comparison to open surgery. J Pediatr Urol 2014;10:875-879.

14. Arlen AM, Broderick KM, Travers C, Smith EA, Elmore JM, Kirsch AJ. Outcomes of complex robot-assisted extravesical ureteral reimplantation in the pediatric population. J Pediatr Urol 2016;12:169. e1-e6.

15. Herz D, Fuchs M, Todd A, McLeod D, Smith J. Robotassisted laparoscopic extravesical ureteral reimplant: A critical look at surgical outcomes. J Pediatr Urol 2016;12: 402. e1-e9.

16. Boysen WR, Ellison JS, Kim C, et al. Multi-institutional review of outcomes and complications of robot-assisted laparoscopic extravesical ureteral reimplantation for treatment of primary vesicoureteral reflux in children. J Urol 2017;197:1555-1561.

Address correspondence to: Craig A. Peters, MD Division of Pediatric Urology Children's Health Texas 2350 N Stemmons Freeway, Ste. 4300, MC: F4.04 Dallas, TX 75207 USA

E-mail: craig.peters@utsouthwestern.edu

\section{Abbreviation Used}

HIdES $=$ hidden incision endoscopic surgery 